\title{
NUMERICAL SIMULATION OF POWDER-SNOW AVALANCHES
}

\author{
By Yusuke FuKushima
}

(Faculty of Engineering, Nagaoka University of Technology, Nagaoka, Niigata, Japan)

and GARY PARKER

(St. Anthony Falls Hydraulic Laboratory, University of Minnesota, Minneapolis, Minnesota 55414,

\begin{abstract}
Appropriate expressions describing the motion of powder-snow avalanches are derived. The model consists of four equations, i.e. the conservation equations of fluid mass, snow-particle mass, momentum of the cloud, and kinetic energy of the turbulence. Insofar as the density difference between the avalanche and the ambient air becomes rather large compared with the density of the ambient air, the Boussinesq approximation, which is typically used to analyze density currents, cannot be adopted in the present case. As opposed to previous models, the total buoyancy of a powder-snow avalanche is allowed to change freely via erosion from and deposition on to a static snow layer on a slope. In the model, the snow-particle entrainment rate from the slope is directly linked to the level of turbulence.
\end{abstract}

A discontinuous, large-scale powder-snow avalanche occurred on 26 January 1986 near Maseguchi, Niigata Prefecture, Japan. The avalanche appears to have had a dense core at its base. The present model is employed to simulate that part of the avalanche above any dense core. The depth of the layer of fresh snow is considered to be an important parameter in the model. The larger the depth of fresh snow, the larger is the concentration of snow attained in the avalanche, and the faster its speed. It is seen that the model provides a reasonable description of the powder-snow avalanche generated near Maseguchi. In particular, the model prediction that a powder-snow avalanche strong enough to reach Maseguchi requires a depth of fresh snow of at least $2 \mathrm{~m}$ is in agreement with the observed depth just before the event.

\section{INTRODUCTION}

A strong powder-snow avalanche occurred recently near the town of Maseguchi, Niigata Prefecture, Japan. The avalanche was generated at $23.00 \mathrm{~h}$ on 26 January 1986, on the steep slope of Mount Gongen, which is located near Maseguchi. Eleven houses were destroyed, and 13 people were killed by the avalanche. The horizontal distance between Mount Gongen and Maseguchi is about $1800 \mathrm{~m}$. The steepest angle of slope of Mount Gongen is about $50^{\circ}$. The end of the zone of avalanche deposition, where the avalanche came to rest, was clearly demarcated by the distribution of destroyed and undamaged houses in the village. The release zone, i.e. the zone where the avalanche commenced, and its course can be estimated from topographical maps and aerial photographs taken $4 \mathrm{~d}$ after the accident.

Powder-snow avalanches are discontinuous flows moving over inclined boundaries, in which heavy snow particles are suspended in air. They often develop from dense snow-slab avalanches, in which grain flow dominates and suspension is minimal (Hopfinger, 1983). Powder-snow avalanches may be distinguished from flowing avalanches in terms of concentration. The former constitute suspensions of snow in air that are dilute in the volumetric sense, whereas in the case of the latter the volume concentrations of snow and air are comparable to each other. Flowing avalanches are not treated in the present analysis.

The driving force of powder-snow avalanches is the down-slope component of the effective weight depending on the density difference between the air-snow mixture in an avalanche and the ambient clear air. Snow particles are suspended by the turbulence in an avalanche; they are deposited in the absence of a sufficient level of turbulence. The turbulence itself is produced by the mean motion of the avalanche.

The size of an avalanche tends to increase in time due to the entrainment of ambient air by turbulence. Turbulence thus plays an essential role in the mechanics of powdersnow avalanches. If the production of turbulence created by the mean motion becomes larger than the sum of the consumption of turbulence by the suspension of heavy particles and viscous dissipation, the powder-snow avalanche can accelerate and grow to substantial size, to the extent that sufficient snow supply is available from the bed for entrainment into the current. In this case, the ultimate size is probably determined by the supply of entrainable snow and the slope profile. Otherwise, the powder-snow avalanche cannot maintain itself in motion. Turbidity currents in the ocean and large lakes, in which sand particles instead of snow particles are suspended in water, are close relatives of powder-snow avalanches (Luthi, 1981; Simpson, 1982).

Powder-snow avalanches are observed in many mountainous areas. It is widely recognized that they can constitute dangerous natural disasters. Hopfinger (1983) has summarized information on the mechanics of avalanches in general, and powder-snow avalanches in particular. Hopfinger indicated that powder-snow avalanches are often formed when the velocity of a slab avalanche reaches approximately $10 \mathrm{~m} \mathrm{~s}^{-1}$. Well-developed powder-snow avalanches have heights as high as $100 \mathrm{~m}$ (Voellmy, 1955; Hopfinger, 1983). There is apparently no simple correlation between front velocity and slope angle. The process of formation of powder-snow avalanches appears to be very rapid.

Atmospheric thermals, and conservative density clouds moving down inclined slopes, are simpler relatives of powder-snow avalanches. Theories of these two phenomena have been developed by many researchers (Morton and others, 1956; Escudier and Maxworthy, 1973; Hopfinger and Beghin, 1980; Beghin and others, 1981; Simpson, 1982). The basis of thermal theory consists of the relations of mass and momentum conservation, together with appropriate assumptions concerning the entrainment of ambient fluid and similarity of thermal shape. Escudier and Maxworthy (1973) discussed the entrainment rate of ambient fluid for "non-Boussinesq" thermals, for which the density difference between thermal and ambient fluid is large, so that the Boussinesq assumption cannot be used. Escudier and Maxworthy's conclusions are that the entrainment rate of a vertical thermal of given length scale is almost independent of the density difference, and that the value of the non- 
dimensional entrainment rate is nearly constant for largescale thermals. Hopfinger and Beghin (1980) and Beghin and others (1981) extended thermal theory to both Boussinesq and non-Boussinesq density clouds on inclined boundaries. They were motivated by an interest in powder-snow avalanches. Their experimental results suggest that thermal theory is applicable to density clouds on inclined boundaries with slope angles in the range $10-90^{\circ}$

Turbidity currents, which occur in the ocean and large lakes, are close cousins of powder-snow avalanches. Recently, Pantin (1979), Parker (1982), Fukushima and others (1985), and Parker and others (1986) developed a theory of continuous turbidity currents. Both Pantin and Parker found that the erosion and deposition of bed material allow for the possibility of self-acceleration; Parker called the phenomenon "ignition". In the analyses of Pantin and Parker, water entrainment is neglected. Parker and others (1986) obtained layer-averaged equations of motion for a continuous turbidity current, i.e. the equations of fluid mass, sediment mass, momentum conservation, and mean energy of the turbulence, in which the entrainment of water from above and sediment from below are considered.

An important assumption of the models of Fukushima and others (1985) and Parker and others (1986) is that the water and sediment supply to the turbidity current at the up-stream end is continuous. Fukushima and Parker (1984) and Fukushima (1986) extended these analyses to the discontinuous case, so as to encompass powder-snow avalanches as well. Fukushima (1986) developed a theory of powder-snow avalanches along a varying slope. Fukushima's model is derived from thermal theory as described above, but with additional assumptions. In the theory, a powder-snow avalanche originating from an instantaneous source at the up-stream end is considered. The suspension of snow particles is considered to be dilute, i.e. $C \ll 1$, where $C$ is the average volumetric concentration of snow particles in an avalanche. The relative density difference
$R C /(1+R C)$, however, may vary in the range $0<R C /(1+R C)<1$, where $R$ is the immersed specific gravity of the snow particles. It thus follows that the Boussinesq approximation cannot be used.

The present analysis incorporates the possibility of ignition, or self-acceleration. That is, a sufficiently swift powder-snow avalanche may suspend more snow, become heavier, and further accelerate in a self-reinforcing cycle. A perusal of recent work on avalanches by Salm and Gubler (1987) suggests that this feature is missing from previous models.

The powder-snow avalanche at Maseguchi is simulated numerically in the present paper. The depth of the layer of fresh, loose snow available for entrainment (and thus available to drive self-acceleration) is found to be an important parameter in the simulation.

\section{THE POWDER-SNOW AVALANCHE AT MASEGUCHI}

A strong powder-snow avalanche occurred at Maseguchi, Niigata Prefecture, Japan, at $23.00 \mathrm{~h}$ on 26 January 1986 (Fukushima, 1986; Kobayashi and Izumi, 1988). The powder-snow avalanche may have had a dense slab avalanche at its core. The avalanche was generated on the steep slopes of Mount Gongen, and flowed as far as the middle of Maseguchi Village, where 11 houses were destroyed and 13 people were killed. The topography near Maseguchi and Mount Gongen is illustrated in Figure 1. The latitude and longitude of Maseguchi are $37^{\circ} 02^{\prime} \mathrm{N}$. and $138^{\circ} 04^{\prime} \mathrm{E}$, respectively. Mount Gongen, the elevation of which is $1108 \mathrm{~m}$, is located south-west of Maseguchi; the horizontal distance between the summit and the near edge of Maseguchi Village is about $1800 \mathrm{~m}$. The damaged houses were located in the shaded area in Figure 1, demarcating the point of termination of the avalanche. Meteorological observations were available from a weather station located

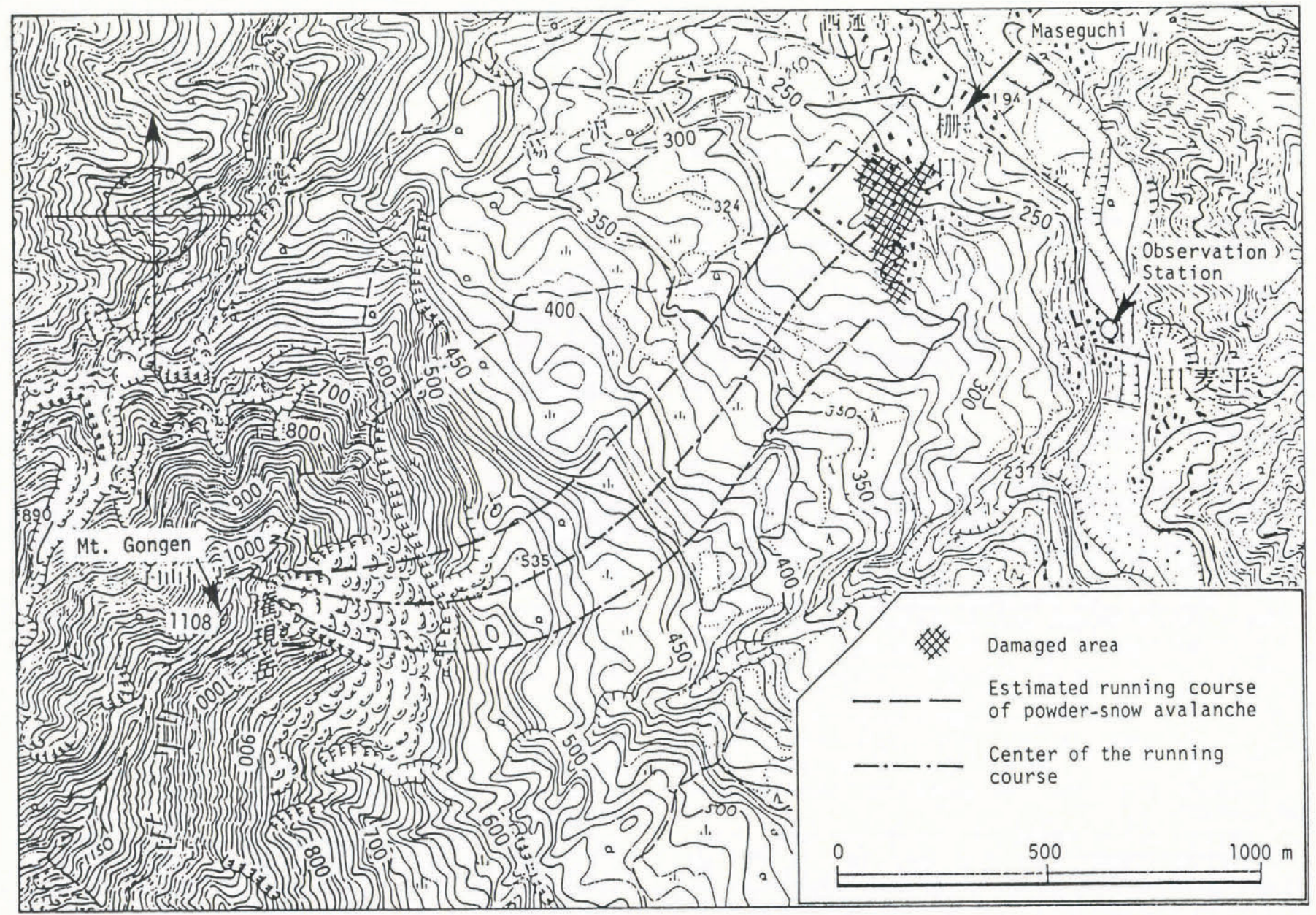

Fig. 1. Topographical map near Maseguchi, where a severe natural disaster due to a powder-snow avalanche occurred on 26 January 1986. The area damaged by the powder-snow avalanche is highlighted by the hatching. The width and center of the running course of the avalanche are shown by dashed lines and a chain line, respectively. 
$500 \mathrm{~m}$ to the south-east of Maseguchi. The depth of snow-pack observed at the station on 20 January was $185 \mathrm{~cm}$. After a heavy snowstorm, the depth increased to $330 \mathrm{~cm}$ on 25 January, $370 \mathrm{~cm}$ on 26 January, and $440 \mathrm{~cm}$ on 27 January, respectively. No data for Mount Gongen are available. It may be inferred that the depth of snow-pack on the mountainside traversed by the avalanche was over $400 \mathrm{~cm}$, due to the fact that the mountainside is approximately $200 \mathrm{~m}$ higher than the observation station. The temperatures recorded at the station between 25 and 27 January were in the range $-2.3^{\circ}$ to $0.2^{\circ} \mathrm{C}$. Therefore, the new snow accumulated after 21 January from Mount Gongen to Maseguchi was likely dry and non-cohesive. A dense layer of fresh snow was observed to extend at least $200 \mathrm{~cm}$ below the surface. Thus, a layer $200-300 \mathrm{~cm}$ in thickness was available to contribute to the formation of a powder-snow avalanche via entrainment into the current.

The zone of generation and the course of the avalanche can be estimated with the aid of topographical maps, as well as an aerial photograph taken on 30 January, just after the accident (Niigata Prefecture, 1986; Niigata Regional Meteorological Observatory, 1986). The zone of generation of the avalanche was apparently near the summit of Mount Gongen. The avalanche then flowed down a gentle valley to the east of Mount Gongen. The estimated course of the avalanche is shown in Figure 1 by the broken line. The width of the avalanche was estimated as $200 \mathrm{~m}$. A longitudinal section along the course of the avalanche is shown in Figure 2, in which the scales have not been distorted. It is seen that the slope of the course varies

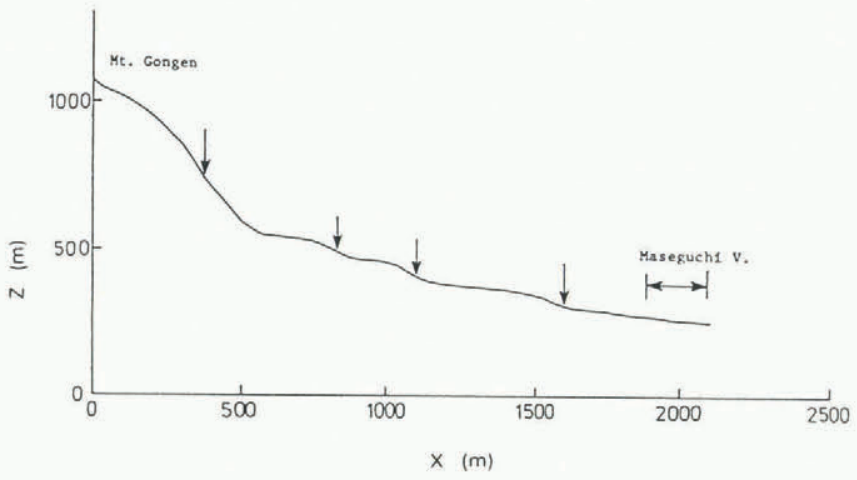

Fig. 2. Longitudinal section along the estimated running course of the powder-snow avalanche. Note that the vertical axis is not exaggerated. Arrows indicate places where the slope angle is relatively steep.

considerably. The largest slope angle of $50^{\circ}$ is near the sumit of Mount Gongen. Below an elevation of $500 \mathrm{~m}$, the slope drops off; the slope angle near Maseguchi is smaller than $5^{\circ}$. The arrows in the figure indicate relatively steep zones along the course of the avalanche. It is reported that small-scale avalanches frequently occur on the slope of Mount Gongen because of the topographic characteristics and the large amount of snow typically present in the winter (Niigata Prefecture, 1986).

\section{THEORY OF POWDER-SNOW AVALANCHES}

A schematic diagram of a two-dimensional powdersnow avalanche is shown in Figure 3. Consider the motion of a powder-snow avalanche into still ambient air of density $\rho_{\mathrm{a}}$. Fukushima (1986) has derived the basic equations of powder-snow avalanches based on thermal theory. His model differs from the thermal model in the following ways: (a) the total buoyancy of the avalanche varies freely via erosion and deposition of snow; (b) a treatment of the conservation of kinetic energy of turbulence is included; and (c) the angle of the slope varies in the flow direction. In addition, the effects of shear stress acting on both the upper boundary (interface) and the lower boundary (bed) are considered. The shear stress acting at the lower boundary plays an essential role as regards the suspension and deposition of snow particles. The velocity and density in the avalanche are approximated as uniform.

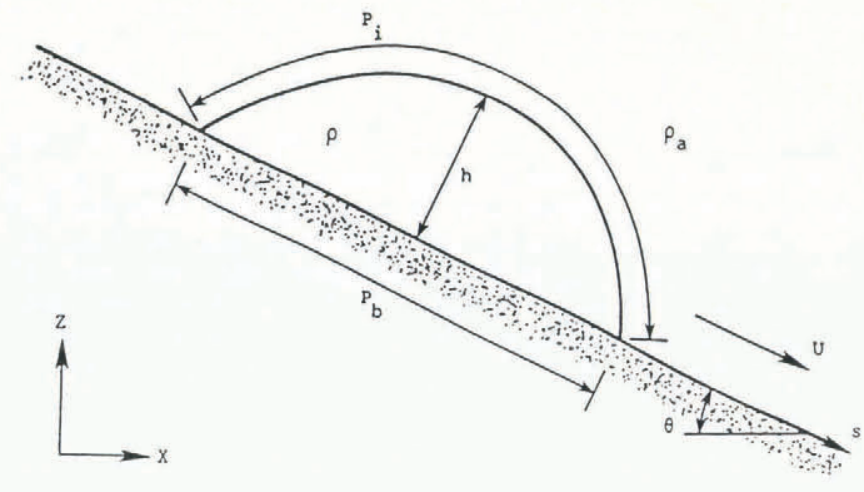

Fig. 3. Schematic diagram of a two-dimensional powdersnow avalanche.

Here, the shape of the avalanche is assumed to be a cylinder of half-elliptic section at a given slope angle $\theta$ (Fig. 3). The transverse width of this cylinder is taken to be constant, in accordance with Figure 1. The resulting model applies only to avalanches that do not show significant transverse spreading. The area $A$, the perimeter of the upper boundary $P_{\mathrm{i}}$ and the perimeter of the lower boundary $P_{\mathrm{b}}$ of the avalanche are expressed as

$$
A=\xi_{\mathrm{A}} h^{2} ; \quad P_{\mathrm{b}}=\xi_{\mathrm{b}} h ; \quad P_{\mathrm{i}}=\xi_{\mathrm{i}} h
$$

where $h$ is the height of the avalanche and the shape factors $\xi_{\mathrm{A}}, \xi_{\mathrm{b}}$, and $\xi_{\mathrm{i}}$ are considered to be functions of slope angle $\theta$.

The equations of conservation of avalanche fluid mass, snow mass, momentum, and kinetic energy of the turbulence, respectively, can be expressed in the form

$$
\begin{gathered}
\frac{\mathrm{d} A}{\mathrm{~d} t}=E_{\mathrm{w}} U P_{\mathrm{i}} \\
\frac{\mathrm{d}}{\mathrm{d} t} C A=v_{\mathrm{s}}\left(E_{\mathrm{s}}-c_{\mathrm{b}} \cos \theta\right) P_{\mathrm{b}} \\
\frac{\mathrm{d}}{\mathrm{d} t}\left(\rho+k_{\mathrm{v}} \rho_{\mathrm{a}}\right) U A=\left(\rho-p_{\mathrm{a}}\right) g A \sin \theta-\tau_{\mathrm{i}} P_{\mathrm{i}}-\tau_{\mathrm{b}} P_{\mathrm{b}} \\
\frac{\mathrm{d}}{\mathrm{d} t}\left(\rho+k_{\mathrm{v}} \rho_{\mathrm{a}}\right) K A=U\left(\tau_{\mathrm{i}} P_{\mathrm{i}}+\tau_{\mathrm{b}} P_{\mathrm{b}}\right)+ \\
+\frac{1}{2} \rho_{\mathrm{a}}\left\{\left(1+k_{\mathrm{v}}\right) E_{\mathrm{w}} U P_{\mathrm{i}}+R v_{\mathrm{s}}\left(E_{\mathrm{s}}-c_{\mathrm{b}} \cos \theta\right) P_{\mathrm{b}}\right\} U^{2}- \\
-\rho_{\mathrm{a}} R g C v_{\mathrm{s}} A-\xi_{\mathrm{p}} \rho R g \cos \theta h\left(\frac{1}{2} C E_{\mathrm{w}} U P_{\mathrm{i}}+\right. \\
\left.+v_{\mathrm{s}}\left(E_{\mathrm{s}}-c_{\mathrm{b}} \cos \theta\right) P_{\mathrm{b}}\right\}-E .
\end{gathered}
$$

Here $E_{w}$ is a coefficient of entrainment of ambient air into the avalanche, and $U$ is the velocity at the mass center of the avalanche. $P_{\mathrm{i}}$ and $P_{\mathrm{b}}$ denote the lengths of the upper and lower perimeters, respectively. $C$ is the mean volume concentration of snow particles in the avalanche, $c_{b}$ is the near-bed concentration, $v_{S}$ is the fall velocity of snow particles in still air, and $E_{\mathrm{S}}$ is an entrainment coefficient expressing the volumetric rate of incorporation of snow particles into air. The virtual mass coefficient $k_{\mathrm{v}}$ is assumed to depend on the shape of the avalanche, and thus on the slope angle $\theta$ only; $\tau_{\mathrm{i}}$ and $\tau_{\mathrm{b}}$ are shear stresses acting on the upper and the lower boundaries, respectively. Also, $\rho$ and $\rho_{\mathrm{b}}$ denote the average density of the avalanche and the near-bed density, respectively; $\xi_{p}$ is a coefficient related to the potential energy of suspended snow particles.

$K$ denotes the average kinetic energy in an avalanche, defined as

$$
K=\frac{1}{\rho A} \int_{A} \tilde{\rho} \frac{1}{\left.\frac{1}{\left(u^{\prime 2}+v^{\prime 2}+w^{\prime 2}\right.}\right)} \mathrm{d} A
$$


where $\tilde{\rho}$ denotes the local density in the avalanche and $u^{\prime}$, $v^{\prime}$, and $w^{\prime}$ are the components of fluctuating velocity in the $x, y$, and $z$-directions, respectively. Here, $K$ is referred to as the level of turbulence.

In Equation (3), the term $v_{\mathrm{s}} c_{\mathrm{b}} P_{\mathrm{b}} \cos \theta$ denotes the deposition rate of snow from the avalanche and $v_{\mathrm{s}} E_{\mathrm{s}} P_{\mathrm{b}}$ denotes the entrainment rate of snow particles from the bed into the avalanche. Thus, the right-hand side of Equation (3), i.e. $v_{\mathrm{s}}\left(E_{\mathrm{s}}-c_{\mathrm{b}} \cos \theta\right) P_{\mathrm{b}}$, expresses the net rate of entrainment of snow particles from the lower boundary (erosion minus deposition). From the condition of continuity of bed material, the erosion rate of the bed $\eta_{b}$ is given by

$$
\eta_{\mathrm{b}}=\frac{1}{1-\lambda} v_{\mathrm{s}}\left(E_{\mathrm{s}}-\cos \theta\right)
$$

where $\lambda$ is the porosity of the snow layer.

The mean density $\rho$ of the avalanche and the near-bed density $\rho_{\mathrm{b}}$ are related to the corresponding volumetric concentrations as follows: $\rho=\rho_{\mathrm{a}}(1+R C)$, and $\rho_{\mathrm{b}}=\rho_{\mathrm{a}}(1+$ $\left.R c_{\mathrm{b}}\right)$, where $R=\left(\rho_{\mathrm{S}}-\rho_{\mathrm{a}}\right) / \rho_{\mathrm{a}}$ is the immersed specific gravity of snow particles in air, and $\rho_{\mathrm{S}}$ is the density of snow particles. The maximum value of $R$, i.e. the case of solid ice particles in air at $0^{\circ} \mathrm{C}$, is near 710 . The product $R C$ thus becomes large, and the usual Boussinesq assumption fails, even for a quite dilute volumetric concentration $C$.

For the case of a cloud containing a conservative contaminant (e.g. a saline thermal in water), the right-hand side of Equation (3) is zero and the total buoyancy remains constant in time, so that $C A$ is invariant. In addition, if the shear stresses in Equation (4) can be neglected and the down-stream slope of the boundary is constant, the set of Equations (2), (3), (4) has the analytical solutions found by Beghin and others (1981).

The physical meaning of the terms in Equation (5) are essentially the same as those of the layer-averaged balance of continuous turbidity currents obtained by Parker and others (1986). The first two terms on the right-hand side of Equation (5) denote the turbulent-energy production caused by the shear stresses acting on the upper and lower boundaries, respectively. The next two terms denote the turbulent-energy production caused by the loss of mean flow energy associated with the acceleration of newly entrained ambient fluid from above and snow particles from the lower boundary, respectively. The sixth term is the Knapp-Bagnold term (Knapp, 1938; Bagnold, 1962), which expresses the work necessary to maintain snow particles in suspension. The potential energy of an avalanche is always increased by turbulence with the aid of the entrainment of air; the energy of the turbulence is thus decreased. This effect is expressed by the seventh term. The potential energy may also change through the expenditure of turbulent energy in eroding new snow from the bed. This is embodied in the eighth term of Equation (5). The term can be positive or negative depending upon whether or not the entrainment rate $E_{\mathrm{s}} v_{\mathrm{s}}$ exceeds the deposition rate $v_{\mathrm{s}} c_{\mathrm{b}} \cos \theta$ The ninth and final term, $E$, denotes the rate of viscous dissipation of turbulent energy.

Parker and others (1986) obtained an energy constraint on continuous turbidity currents as an extension of the so-called Knapp-Bagnold constraint; these flows are close relatives of powder-snow avalanches. An analogous constraint for a discontinuous powder-snow avalanche can be obtained from Equation (5). The viscous dissipation in a cloud $E$ is always positive, so that, if the inequality

$$
\begin{gathered}
U\left(\tau_{\mathrm{i}} P_{\mathrm{i}}+\tau_{\mathrm{b}} P_{\mathrm{b}}\right)+\frac{1}{2} \rho_{\mathrm{a}}\left\{\left(1+k_{\mathrm{v}}\right) E_{\mathrm{w}} U P_{\mathrm{i}}+\right. \\
\left.+R v_{\mathrm{s}}\left(E_{\mathrm{s}}-c_{\mathrm{b}} \cos \theta\right) P_{\mathrm{b}}\right\} U^{2}- \\
-\rho_{\mathrm{a}} R g C v_{\mathrm{s}} A-\xi_{\mathrm{p}} \rho R g \cos \theta h\left(\frac{1}{2} C E_{\mathrm{w}} U P_{\mathrm{i}}+\right. \\
\left.\quad+v_{\mathrm{s}}\left(E_{\mathrm{s}}-c_{\mathrm{b}} \cos \theta\right)\right\} P_{\mathrm{b}} \geqslant 0
\end{gathered}
$$

fails to be satisfied for a sufficiently long time, the turbulence must die. Under these circumstances, snow particles would fall out of suspension, and the avalanche would die as well.
In order to analyze powder-snow avalanches in the context of Equations (2), (3), (4), and (5), additional assumptions are necessary to close the system; these include the functional forms of the shape factors, and the constitutive relationships for the shear stresses, the viscous dissipation, and the entrainment coefficients of air and snow.

Hopfinger and Beghin (1980) and Beghin and others (1981) assumed that the shape of simple density clouds can be approximated by a half-ellipse. The shape factors $\xi_{\mathrm{A}}, \xi_{\mathrm{i}}$, $\xi_{\mathrm{p}}$, and the virtual mass coefficient $k_{\mathrm{v}}$ are given by

$$
\begin{array}{ll}
\xi_{\mathrm{A}}=\frac{\pi}{4} \xi_{\mathrm{b}} ; & \xi_{\mathrm{i}}=\frac{\pi}{2(2)^{\frac{1}{2}}}\left\{\left(4 \xi_{\mathrm{b}}{ }^{-2}+1\right)\right\}^{\frac{1}{2}} \xi_{\mathrm{b}} \\
\xi_{\mathrm{p}}=\frac{4}{3} \pi ; & k_{\mathrm{v}}=\frac{2}{\xi_{\mathrm{b}}} .
\end{array}
$$

According to the experimental data of Beghin and others $(1981), \xi_{\mathrm{b}}$ may be specified as

$$
\xi_{\mathrm{b}}=8.47 \theta^{-1 / 3}
$$

where $\theta$ is the slope angle in degrees. The relation (10), which is obtained from experiments with a constant slope angle, is here assumed to apply to powder-snow avalanches flowing down-slope with variable slope angle.

The fluid-entrainment coefficient is expected to be a strong function of slope angle. Beghin and others (1981) reported that the fluid-entrainment rate of inclined thermals depends approximately linearly on slope angle $\theta$, although their experimental values seem quite large. Escudier and Maxworthy (1973) collected field and laboratory data for three-dimensional vertical thermals. An appropriate value of the fluid-entrainment coefficient for three-dimensional vertical thermals is near 0.1 . Here, the following simple relation is assumed:

$$
E_{\mathrm{w}}=0.1 \theta / 90^{\circ} \text {. }
$$

The determination of the coefficient of bed-snow entrainment $E_{\mathrm{S}}$ is made difficult by the paucity of measurements for snow in air. Extensive measurements are, however, available for sand in water. In the interest of facilitating the calculation, a rather bold application of a relation for sand in water to snow in air is made.

Fukushima and others (1985) and Parker and others (1986) have used the following relations for $E_{\mathrm{S}}$ and $r_{0}\left(=c_{\mathrm{b}} / C\right)$ in the analysis of continuous turbidity currents:

$$
E_{\mathrm{s}}= \begin{cases}0 & Z<Z_{\mathrm{c}} \\ 3.0 \times 10^{-12} Z^{10}\left(1-Z_{\mathrm{c}} / Z\right) & Z_{\mathrm{c}} \leqslant Z<Z_{\mathrm{m}} \\ 0.3 & Z_{\mathrm{m}}<Z\end{cases}
$$

and

$$
r_{0}=1+31.5 \mu^{-1.46}
$$

where

$$
\begin{aligned}
& Z=\left(R_{\mathrm{p}}\right)^{\frac{1}{2}} \mu \\
& \mu=\frac{\left(\tau_{\mathrm{b}} / \rho_{\mathrm{b}}\right)^{\frac{1}{2}}}{v_{\mathrm{s}}}
\end{aligned}
$$

and $R_{\mathrm{p}}=\left(R g D_{\mathrm{s}}\right)^{\frac{1}{2}} D_{\mathrm{s}} / v$ is the particle Reynolds number, $v$ is the kinematic viscosity of water, $D_{\mathrm{S}}$ is the diameter of the particles, and $\mu$ is a non-dimensional bed-shear velocity. In Equation (12), $Z_{\mathrm{c}}=5$ and $Z_{\mathrm{m}}=13.2$ are the critical and the maximum values of $Z$, respectively.

The relations (12)-(15) were originally obtained for equilibrium suspensions of sand in open-channel flow (Parker, 1982; Akiyama and Fukushima, 1985). Those relations have been tested experimentally for the case of 
steady, continuous turbidity currents by Garcia (unpublished). Although the scatter is large, both Equations (12) and (13) provide approximate explanations of the experimental data for sand-laden turbidity currents as well. Here, Equations (12) and (13) are applied to powder-snow avalanches in the absence of any better information. The dependence of the model on Equations (12) and (13), and issues of relevance considering the degree of extrapolation, are discussed in section 5 .

Shear stresses are typically linked to the mean velocity in the following fashion:

$$
\tau_{\mathrm{i}} / \rho_{\mathrm{a}}=c_{\mathrm{Di}} U^{2} ; \quad \tau_{\mathrm{b}} / \rho_{\mathrm{b}}=c_{\mathrm{Db}} U^{2}
$$

where $c_{\mathrm{Di}}$ and ${ }^{c_{\mathrm{Db}}}$ are the friction coefficients of the upper and lower boundaries, respectively. Based on the above assumptions, the three equations of balance of fluid mass, snow mass, and momentum are closed, and decoupled from the equation of balance of turbulent kinetic energy. This simple three-equation model, however, of ten fails to satisfy the energy constraint analogous to Equation (8) for the case of accelerating turbidity currents, as shown by Parker and others (1986).

Here, the shear stresses and the energy dissipation in an avalanche are alternatively expressed by the following relations:

$$
\tau_{\mathrm{i}} / \rho_{\mathrm{a}}=\alpha_{\mathrm{i}} K ; \quad \tau_{\mathrm{b}} / \rho_{\mathrm{b}}=\alpha_{\mathrm{b}} K
$$

and

$$
E=B \rho_{\mathrm{a}} \frac{E^{3 / 2} A}{h}
$$

where the non-dimensional coefficients $\alpha_{\mathrm{i}}, \alpha_{\mathrm{b}}$, and $\beta$ are considered to be constant for simplicity. The snow entrainment is directly linked to the level of turbulence through Equations (17) and (18). The Equations (2), (3), and (5), in conjunction with Equations (12)-(15), (17), and (18) constitute a four-equation model for powder-snow avalanches.

In the four-equation model, the values of $\alpha_{i}, \alpha_{b}$, and $\beta$ must be specified, as opposed to $c_{\mathrm{Di}}, c_{\mathrm{Db}}$, which must be specified in the three-equation model. The non-dimensional coefficient $B$, which is related to the energy dissipation in an avalanche, is the least well known of the coefficients. Based on some rather crude but plausible assumptions, however, $B$ can be related to the other coefficients as follows.

Neither the three-equation nor the four-equation model for powder-snow avalanches possess analytical solutions. For the case of a conservative cloud on a constant slope, however, both models have asymptotic solutions applicable at $t \rightarrow \infty$. If it is required that both models predict exactly the same asymptotic solution for conservative currents, the following relation is obtained:

$$
\begin{aligned}
& B=\frac{1}{\xi_{\mathrm{A}}}\left(\frac{\alpha}{c_{\mathrm{D}}}\right)^{3 / 2}\left\{\left(\xi_{\mathrm{i}}+\xi_{\mathrm{b}}\right) c_{\mathrm{D}}+\left(1-\frac{c_{\mathrm{D}}}{\alpha}\right) \frac{\mathrm{t}}{2}\left(1+k_{\mathrm{v}}\right) \xi_{\mathrm{i}} E_{\mathrm{w}}-\right. \\
& \left.-\xi_{\mathrm{p}} \cot \theta \frac{\xi_{\mathrm{i}} E_{\mathrm{w}}}{2 \xi_{\mathrm{A}}}\left[3 / 4\left(1+k_{\mathrm{v}}\right) \xi_{\mathrm{i}} E_{\mathrm{w}}+\left(\xi_{\mathrm{i}}+\xi_{\mathrm{b}}\right) c_{\mathrm{D}}\right]\right\}
\end{aligned}
$$

in which

$$
c_{\mathrm{D}}=c_{\mathrm{Di}}=c_{\mathrm{Db}} ; \quad \alpha=\alpha_{\mathrm{i}}=\alpha_{\mathrm{b}} .
$$

The various shape factors and coefficients included in Equation (19) are mostly functions of slope angle $\theta$, so that $\beta$ is also a function of $\theta$.

The dependency of the four-equation model on the closure parameter $\alpha$ was investigated by means of preliminary calculations. The time-dependent behavior of simple conservative density clouds was calculated by means of the three-equation model and the four-equation model, with various values of $c_{\mathrm{D}}$. The numerical results are almost independent of $\alpha$, over the range $0.05<\alpha<0.2$ and over a wide range of values $c_{\mathrm{D}}$. The difference between the three-equation model and the four-equation model was also found to be very small. Therefore, a constant value of $\alpha=$ 0.1 is adopted in this paper. The same value of $\alpha$ was justifed and used in the prediction of continuous turbidity currents by Fukushima and others (1985), and Parker and others (1986), and is employed here as well in the absence of better information.

\section{NUMERICAL SIMULATION OF THE POWDER-SNOW AVALANCHE AT MASEGUCHI}

In this section, the previously described powder-snow avalanche near Maseguchi, Niigata Prefecture, Japan, is simulated by the four-equation model. The calculations were performed with a desk-top microcomputer. It should be emphasized that the analysis applies only to that part of the avalanche that was dilute in the volumetric sense. The analysis does not describe the behavior of any dense material that may have been present at the core of the powder-snow avalanche. The distinction is important, in that it has been suggested that flowing avalanches are potentially much more destructive than powder-snow avalanches in terms of impact force (e.g. Hopfinger, 1983).

The initial condition and the characteristics of the snow entrained into the avalanche at Maseguchi are not known in detail. The values of various parameters may be reasonably set to be $R=710, D_{\mathrm{S}}=0.15 \mathrm{~mm}, c_{\mathrm{D}}=0.02, \alpha=0.1$, and $h_{0}=10 \mathrm{~m}$. Topographical data are available from maps. The initial velocity and concentration of the cloud is taken to be a little larger than those required for sustained selfacceleration (ignition) on the slope near the summit of Mount Gongen; $U_{0}=8.4 \mathrm{~m} \mathrm{~s}^{-1}$ and $C_{0}=0.00065$. Those values of velocity and concentration are probably rather typical for avalanches on Mount Gongen.

In the simulation, the depth of the layer of fresh, non-cohesive snow is expressed by the equivalent depth $D_{\mathrm{e}}$ of pure ice with vanishing porosity. $D_{\mathrm{e}}$ is an important parameter because it determines the availability of new snow to drive avalanche acceleration. In the same manner, the volume of snow particles in the avalanche is expressed by the equivalent volume of pure ice, because the porosity of the snow layer in Equation (5) is another unknown parameter. Two cases are treated in the present simulation:

Case A. The case for which the depth of fresh, erodible snow is so large that it does not constrain the growth of the avalanche.

Case B. The case for which the depth of fresh, erodible snow is finite, so that growth of the avalanche is limited. When the bed is eroded below this depth, the right-hand side of Equation (3) is assumed to vanish. Values of the depth of new snow in terms of equivalent thickness of pure ice $D_{\mathrm{e}}$ of $0.1,0.5$, and $1 \mathrm{~cm}$ are considered.

The results of the numerical simulation for case $A$ are plotted versus horizontal distance $X$ in Figure $4 a-f$. The variation of the height, speed, concentration, relative level of turbulence, total snow volume per unit width, and depth of erosion or deposition are shown in Figure $4 \mathrm{a}-\mathrm{f}$, respectively. In Figure 4a, the longitudinal topography from Mount Gongen to Maseguchi is also plotted. The relatively steep sections are marked by arrows in each figure. It is seen in Figure $4 \mathrm{~b}$ that the powder-snow avalanche acelerates strongly on the steep slope of Mount Gongen, from $10 \mathrm{~m} \mathrm{~s}^{-1}$ near the top to $50 \mathrm{~m} \mathrm{~s}^{-1}$ at the foot of the mountain (near $X=500 \mathrm{~m})$. As the slope angle decreases, the avalanche decelerates, and the velocity quickly decreases to $20 \mathrm{~m} \mathrm{~s}^{-1}$. After that, the avalanche accelerates again on the relatively steep slope near $X=750 \mathrm{~m}$, and the velocity increases to $30 \mathrm{~m} \mathrm{~s}^{-1}$. As the avalanche runs down, it accelerates along reaches of steep slope, marked by an arrow, and decelerates along reaches of gentle slope. The avalanche finally reaches the near end of Maseguchi Village with a velocity of 6-7 $\mathrm{m} \mathrm{s}^{-1}$, and comes to rest near $X=2200 \mathrm{~m}$, at the center of Maseguchi Village. The time elapsed while the avalanche runs from the summit of Mount Gongen to the near end of Maseguchi $(X=1800 \mathrm{~m})$ is about $120 \mathrm{~s}$. Thus, the generation and development of the avalanche is predicted to be very rapid. 

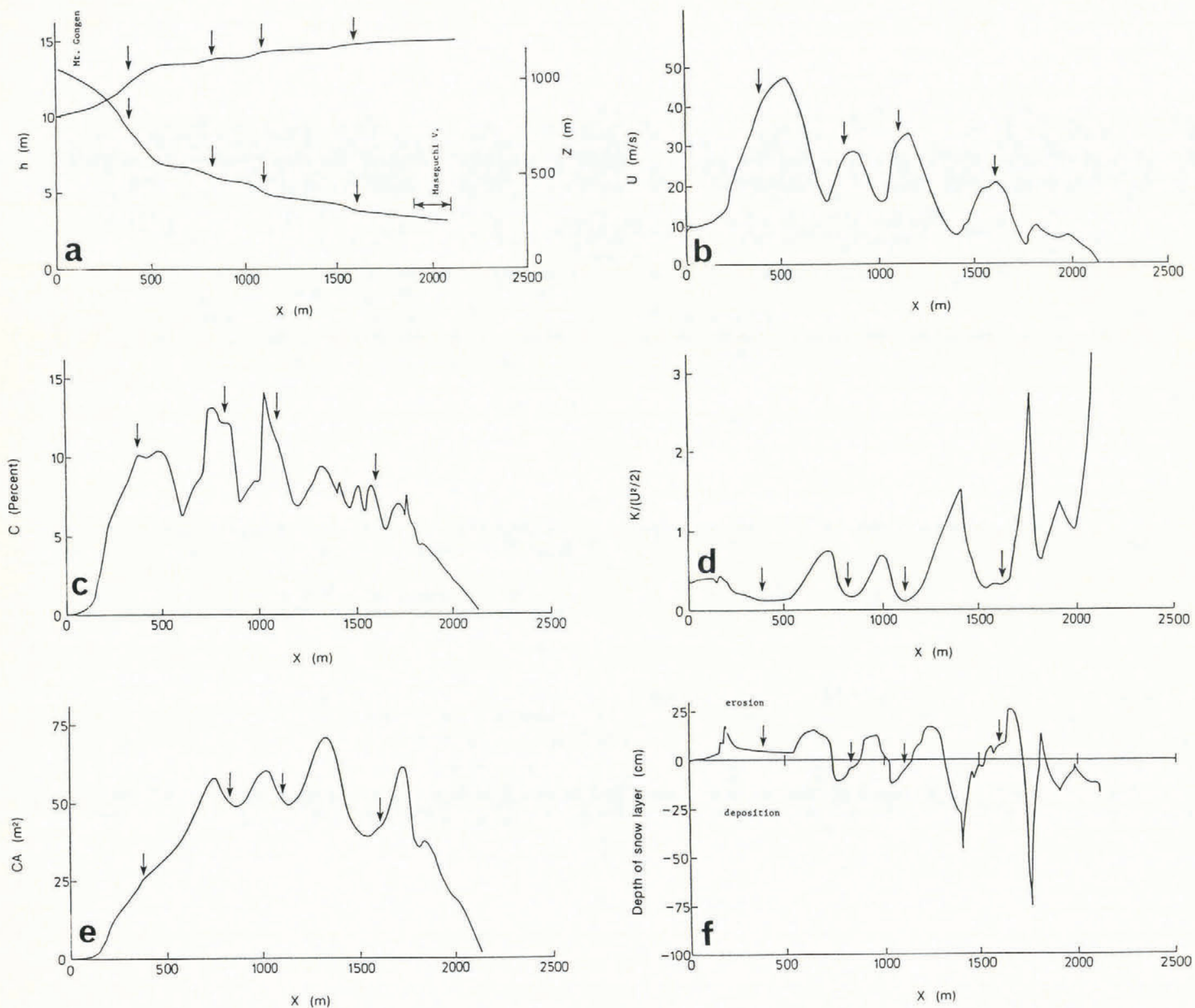

Fig. 4.a. Variation of height of the powder-snow avalanche with horizontal distance $X$ as predicted for case $A$, in which the depth of the layer of fresh snow is large enough so as not to restrict the growth of the avalanche. A longitudinal section from Mount Gongen to Maseguchi is also plotted in the figure. Arrows indicate relatively steep slope sections. The four-equation model is used in the simulation. b. Variation of mass center velocity of the powder-snow avalanche with horizontal distance $X$ as predicted for case A. c. Variation of mean concentration of snow particles in the avalanche with horizontal distance $X$ as predicted for case $A . d$. Variation of relative level of turbulence $2 K / U^{2}$ with horizontal distance $X$ as predicted for case $A$. e. Variation of volume of snow particles in the avalanche with horizontal distance $X$ as predicted for case A. Volume is expressed in terms of the equivalent volume of pure ice with no pores. $f$. Variation of depth of erosion or deposition by the avalanche with horizontal distance $X$ as predicted for case A. Depth is expressed in terms of the equivalent depth of pure ice with no pores.

The variation of the height of the avalanche is shown in Figure 4a. The height of the avalanche increases monotonically. The growth rate of the avalanche is slightly larger on the section of steep slope, as indicated by the arrows in the figure. As shown in Figure 4c, the variation of the mean concentration of the avalanche correlates well with the longitudinal configuration. The mean concentration of the avalanche increases very quickly in the initial stage of formation $(X<300 \mathrm{~m})$. It then decreases along reaches of gentle slope, and increases on steep slopes. Beyond a horizontal distance $X=1300 \mathrm{~m}$, the concentration decreases, albeit with some fluctuations, and vanishes at $X=2200 \mathrm{~m}$. A maximum volume concentration of 0.14 is attained at $X=1100 \mathrm{~m}$.

One of the important assumptions included in the present analysis is that suspension of snow particles is dilute in the sense that $C \ll 1$, thus allowing for the treatment of an avalanche as a mixture of air and snow particles.
From this point of view, the predicted concentrations of snow particles are probably sufficiently low to satisfy this assumption.

Near Maseguchi, the mean volume concentration falls to 0.05 . This value, combined with velocities of 6 or $7 \mathrm{~m} \mathrm{~s}^{-1}$ suggests that the cause of structural damage to Maseguchi Village may have been a dense core at the base of the powder-snow avalanche. The mechanics of flowing avalanches are not described by the present analysis. It may be speculated, however, that a strong powder-snow avalanche can act to maintain a dense core over slopes too low for the flowing avalanche to sustain itself.

The variation of the relative level of turbulence in the avalanche, $2 K / U^{2}$, is plotted against horizontal distance in Figure 4d. The relative level of turbulence also correlates well with the longitudinal configuration; the relative level of turbulence decreases in the accelerating stage and increases in the decelerating stage. As the avalanche runs down near 
taken to be $D_{0}=0.1,0.5$, and $1.0 \mathrm{~cm}$. Assuming that the value of the porosity of the new snow layer is 0.95 , those values translate to 2,10 , and $20 \mathrm{~cm}$ of snow, respectively. The properties of powder-snow avalanches vary depending upon the longitudinal slope configuration, e.g. the slope angle. The variation of avalanche height and relative level of turbulence shown in Figure $5 \mathrm{a}$ and $\mathrm{d}$ is almost identical to that of case A (Fig. 4a and d).

The avalanche speed, mean concentration, snow volume per unit lateral width in the avalanche, and depth of erosion or deposition are strongly dependent upon the depth of fresh snow. In Figure $5 f$, the depth of eroded snow reaches a constant value determined by $D_{\mathrm{e}}$ just after the release of a cloud. Deposition does not occur until $X=1400 \mathrm{~m}$ for each case.

In Figure $5 b$, the avalanche speed is seen to vary with the depth of fresh snow. For the case $D_{\mathrm{e}}=0.1 \mathrm{~cm}$, the supply of snow from the snow layer is low; the speed of the cloud is correspondingly low, and the cloud cannot reach Maseguchi. For the cases $D_{\mathrm{e}}=0.5$ and $1 \mathrm{~cm}$, the variation of cloud velocity is similar to that of case A.

On the other hand, the concentration and the volume of snow in the cloud vary significantly depending upon the depth of new snow, as shown in Figure $5 c$ and e. The values of the concentration of snow in the cloud are on the order of $0.003,0.01$, and 0.02 for $D_{\mathrm{e}}=0.1,0.5$, and $1 \mathrm{~cm}$, respectively.

At the near end of Maseguchi $(X=1800 \mathrm{~m})$, the mean volume concentration for the case $D_{\mathrm{e}}=1 \mathrm{~cm}$ is less than 0.02 , and the corresponding mean density of the cloud is estimated to be $1.8 \%$ of the density of water. It is open to question as to whether or not a cloud with such a low concentration can be termed an avalanche.

It is reported that weak, small-scale avalanches have frequently occurred near Mount Gongen, while a large-scale avalanche such as considered here has not occurred for at least 100 years. It is possible that the frequent occurrence of such weak avalanches may remove the non-cohesive snow particles on a steep slope, thus preventing the occurrence of powder-snow avalanches large enough to produce a disaster.

\section{DISCUSSION}

The models developed here were originally intended for the analysis of accelerating discontinuous turbidity currents in the ocean and large lakes (Fukushima and Parker, 1984). There are, however, few reliable data available for discontinuous turbidity currents. Application of the models is thus restricted to the case of powder-snow avalanches. It is useful to discuss the difference between powder-snow avalanches and discontinuous turbidity currents. A major difference relates to the value of the density difference between the cloud and the ambient fluid. The relative density difference for subaqueous turbidity currents is typically less than 0.1 . The relative density difference for powder-snow avalanches is, on the other hand, on the order of ten (Hopfinger, 1983). It follows that the Boussinesq approximation cannot be employed in the present analysis, if both phenomena are to be described using the same set of equations.

The consequences of this difference are seen more strongly in the conservation equation of kinetic energy of the turbulence. The net solid-particle entrainment rate from the bed $\left(E_{\mathrm{s}}-c_{\mathrm{b}} \cos \theta\right) P_{\mathrm{b}}$ occurs in both the production term and the dissipation term in the turbulent-energy Equation (5). For turbidity currents, the production term associated with $\left(E_{\mathrm{s}}-c_{\mathrm{b}} \cos \theta\right) P_{\mathrm{b}}$ is usually small compared with the production term associated with the water entrainment (as is implied by the Boussinesq approximation). The dissipation term associated with $\left(E_{\mathrm{s}}-c_{\mathrm{b}} \cos \theta\right) P_{\mathrm{b}}$ is thus dominant in the turbulent-energy equation. It is this term that is responsible for the break-down of the three-equation model in the case of initiating turbidity currents.

On the other hand, the production term associated with $\left(E_{\mathrm{s}}-c_{\mathrm{b}} \cos \theta\right) P_{\mathrm{b}}$ for powder-snow avalanches is by no means negligible. If the production term associated with $\left(E_{\mathrm{S}}\right.$ $\left.-c_{\mathrm{b}} \cos \theta\right) P_{\mathrm{b}}$ becomes larger than the corresponding dissipation term, Equation (5) becomes unstable. As the turbulence becomes intense, $\left(E_{\mathrm{S}}-c_{\mathrm{b}} \cos \theta\right) P_{\mathrm{b}}$ becomes positive, so that the turbulence is further intensified by the production term associated with $\left(E_{\mathrm{s}}-c_{\mathrm{b}} \cos \theta\right) P_{\mathrm{b}}$. As the turbulence becomes weak, $\left(E_{\mathrm{s}}-c_{\mathrm{b}} \cos \theta\right) P_{\mathrm{b}}$ becomes negative, forcing the turbulence to become even weaker. As a result, the four-equation model, as applied to snow avalanches, gives very unrealistic solutions for certain combinations of $h_{0}$ and $c_{\mathrm{D}}$. The ratio of the production and dissipation terms associated with $\left(E_{\mathrm{s}}-c_{\mathrm{b}} \cos \theta\right) P_{\mathrm{b}}$ is seen in form (5) to be of the order of $U^{2} / g h$. As shown in Figure $5 \mathrm{~b}$, the ratio $U^{2} / g h$ is determined for each value of $h_{0}$ by the value of $c_{\mathrm{D}}$. For an initial height $h_{0}=10 \mathrm{~m}$, a powdersnow avalanche predicted by the four-equation model with a value of $c_{\mathrm{D}}=0.01$ shows unrealistic oscillatory behavior in the initiating field. Using the values $h_{0}=10 \mathrm{~m}$ and $c_{\mathrm{D}}=$ 0.02 , non-oscillatory numerical solutions are obtained. It is emphasized here that values of initial height cannot be selected arbitrarily, and that $c_{\mathrm{D}}$ must eventually be determined via experiments or field observations.

The values of the initiating conditions for powder-snow avalanches are strongly dependent on the values of the entrainment rate of snow $E_{\mathrm{S}}$, and the ratio of the near-bed concentration to the average concentration, $r_{0}$; thus, relations (12) and (13) used in this paper influence the results to a considerable degree. The behavior of powder-snow avalanches near the initiation point is also strongly dependent on the value of $E_{\mathrm{S}}$ and $r_{0}$. On the other hand, the asymptotic behavior of initiating powder-snow avalanches on constant slopes predicted by both the threeequation model and the four-equation model tends to become independent of $E_{\mathrm{S}}$ and $r_{0}$. For such a cloud, $E_{\mathrm{S}}$ approaches a constant value of 0.3 and $r_{0}$ becomes nearly unity after a relatively short time has elapsed. Nevertheless, the functional relations for snow-entrainment rate must be refined by extensive experiments and observations if the rather crude analysis presented here is to be refined.

The present simulation of the powder-snow avalanche near Maseguchi may not represent its true destructiveness, due to the possible presence of a dense core behaving more like a flowing avalanche. It would be of use to generalize the model to provide for a description of co-existent powder snow and a dense core.

Maseguchi is located in a region with the highest snowfall in Japan, and by some measures the highest in the world. The generation of a powder-snow avalanche as strong as that of January 1986 has not been reported previously. Several reasons for this are as follows. The temperature at Maseguchi in a typical winter is not as low as that in 1986. As a result, in most years the snow becomes wet and cohesive, and is not easily suspended by air. The fresh snow layer laid down from 20 to 26 January, with a depth of over $2 \mathrm{~m}$, was dry and non-cohesive, and easily suspended by air. A sufficient supply of loose snow particles is clearly necessary for the formation of a strong powder-snow avalanche.

\section{CONCLUSIONS}

A theory of powder-snow avalanches is applied to the prediction of a major powder-snow avalanche generated on a varying slope near Maseguchi, Japan.

The simulations indicate that a depth of fresh snow of at least $2 \mathrm{~m}$, i.e. the observed value, is necessary to form a powder-snow avalanche strong enough to reach Maseguchi. It is seen that the characteristics of powder-snow avalanches simulated by the model are strongly correlated to the longitudinal topographical profile, and to the depth of fresh snow. A powder-snow avalanche accelerates on the steeper slopes and decelerates on the gentler slopes. These characteristics of powder-snow avalanches predicted by the model are in general agreement with observations. The model thus can explain the formation, growth, and subsidence of a powder-snow avalanche.

It is emphasized that a description of the entrainment of snow from the bed and deposition on the bed is essential in order to explain both initiating and subsiding powder-snow avalanches. The present analysis applies neither to dense flowing avalanches nor to any dense, slab-like flow at the core of a powder-snow avalanche. 


\section{ACKNOWLEDGEMENTS}

This study was begun during the senior author's sojourn as Visiting Associate Professor at St. Anthony Falls Hydraulic Laboratory, University of Minnesota, U.S.A Funding from the U.S. National Science Foundation (grant No. NSF/EAR8213045) and Sea Grant (grant No. DOC/NA82AA-D-0039) is gratefully acknowledged.

\section{REFERENCES}

Akiyama, J. and Y. Fukushima. 1985. Entrainment of non-cohesive bed sediment into suspension. Minneapolis, MN, St. Anthony Falls Hydraulic Laboratory. University of Minnesota. (External Memorandum 195.)

Bagnold, R.A. 1962. Auto-suspension of transported sediment, turbidity currents. Proc. R. Soc. London, Ser. A, 205, 315-319.

Beghin, P., E.J. Hopfinger, and R.E. Britter. 1981. Gravitational convection from instantaneous sources on inclined boundary. J. Fluid Mech., 107, 407-422.

Escudier, M.P. and T. Maxworthy. 1973. On the formation of turbulent thermals. J. Fluid Mech., 61(3), 541-552.

Fukushima, Y. 1986. Analytical study of powder snow avalanches. J. Jpn. Soc. Snow Ice, 48(4), 189-197.

Fukushima, Y. and G. Parker. 1984. Discontinuous turbidity currents and powder snow avalanches. Fifth Engineering Mechanics Division Specialty Conference, EM Division/ASCE, Laramie, Wyoming. August 1-3, 1984. Proceedings, 839-842.

Fukushima, Y., G. Parker, and H.M. Pantin. 1985. Prediction of ignitive turbidity currents in Scripps Submarine Canyon. Mar. Geol., 67, 55-81.

Garcia, M.H. Unpublished. Experimental study of turbidity currents. (M.S. thesis, University of Minnesota, 1985.)

Hopfinger, E.J. 1983. Snow avalanche motion and related phenomena. Annu. Rev. Fluid Mech., 15, 47-76.

Hopfinger, E.J. and P. Beghin. 1980. Buoyant clouds appreciably heavier than the ambient fluid on sloping boundaries. In Second International Symposium on Stratified Flows, The Norwegian Institute of Technology, Trondheim, Norway, 24-27 June, 1980. Vol. 1, 495-506.
Inman, D.L., C.E. Nordstrom, and R.E. Flick. 1976. Currents in submarine canyons; an air-sea-land interaction. Annu. Rev. Fluid Mech., 8, 275-310.

Knapp, R.T. 1938. Energy balance in stream-flows carrying suspended load. Transactions of the American Geophysical Union, 1, 501-505.

Kobayashi, S. and K. Izumi. 1988. A brief review of the Maseguchi avalanche in Japan in 1986. International Snow Science Workshop, October 12-15. Whistler. Proceedings. Ottawa, Canadian Avalanche Association, 57-62.

Luthi, S. 1981. Experiments on non-channelized turbidity currents and their deposits. Mar. Geol., 40, M59-68.

Morton, B.R., G.I. Taylor, and J.S. Turner. 1956. Turbulent gravitational convection from maintained and instantaneous sources. Proc. R. Soc. London. Ser. A, 234, 1-23.

Niigata Prefecture. 1986. Intermediate report on powder snow avalanche at Maseguchi. Niigata, Niigata Prefecture. (Technical Memorandum.)

Niigata Regional Meteorological Observatory. 1986. Heavy snow fall in Niigata prefecture and powder snow avalanches at Maseguchi from January 21 to 29. Prompt Meteorological Report 1.

Pantin, H.M. 1979. Interaction between velocity and effective density in turbidity flow: phase-plane analysis, with criteria for auto-suspension. Mar. Geol., 31, 59-99.

Parker, G. 1982. Conditions for the ignition of catastrophically erosive turbidity currents. Mar. Geol., 46, 307-327.

Parker, G., Y. Fukushima, and H.M. Pantin. 1986. Selfaccelerating turbidity currents. J. Fluid Mech., 171, $145-181$,

Parker, G,, M. Garcia, Y. Fukushima, and W. Yu. 1987. Experiments on turbidity currents over an erodible bed. J. Hydraul. Res., 25(1), 123-147.

Salm, B. and H. Gubler, eds. 1987. Avalanche formation, movement and effects. International Association of Hydrological Sciences Publication 162 (Symposium at Davos 1986).

Simpson, J.E. 1982. Gravity currents in the laboratory, atmosphere, and ocean. Annu. Rev. Fluid Mech., 14, 213-234.

Voellmy, A. 1955. Über die Zerstörungskraft von Lawinen. Schweiz. Bauztg., 73(12), 159-162; 73(15), 212-217; 73(19), 280-285. 